\title{
AUTOMATIC LIMIT AND SHAKEDOWN ANALYSIS OF 3-D STEEL FRAMES
}

\author{
NGUYEN DANG Hung \\ University of Liège Belgium \\ HOANG VAN LONG \\ University Le Qui Don, Vietnam
}

\begin{abstract}
This paper presents an efficient algorithm for both limit and shakedown analysis of 3-D steel frames by kinematical method using linear programming technique. Several features in the application of linear programming for rigid-plastic analysis of three-dimensional steel frames are discussed, as: change of the variables, automatic choice of the initial basic matrix for the simplex algorithm, direct calculation of the dual variables by primal-dual technique. Some numerical examples are presented to demonstrate the robustness, efficiency of the proposed technique and computer program.

Keywords: Limit analysis; Shakedown analysis; Plastic hinges; Space frames; Linear programming.
\end{abstract}

\section{INTRODUCTION}

The theoretical development of rigid-plastic analysis by linear programming (LP) technique is extensively described in numerous works [1-5]. In this wide subject, we restrict to mention some practical aspects in a computer program, namely CEPAO. This package had been early developed in the Department of Structural Mechanics and Stability of Constructions of the University of Liège by Nguyen-Dang Hung et al. in the 1980's [6-10]. The CEPAO is a unified package devoted to automatically solve the following problems happened for 2-D frames: Elastic analysis, limit rigid-plastic analysis with proportional loadings; step by step elastic-plastic analysis; shakedown analysis with variable repeated loadings; optimal plastic design with fixed loading; optimal plastic design with choice of discrete profiles and stability checks; shakedown plastic design with variable repeated loadings; shakedown plastic design with updating of elastic response in terms of the plastic capacity.

With the CEPAO, efficient choice between statical and kinematical formulations is realised leading to a minimum number of variables and a considerable reduction the dimension of every procedure. The basic matrix of LP algorithm is implemented under the form of a reduced sequential vector, which is modified during each iteration. An automatic procedure is proposed to build up the common characteristic matrices of elastic-plastic or rigid-plastic calculation, particularly the matrix of the independent equilibrium equations. Application of duality aspects in the linear programming technique allows direct calculation of dual variables and avoids expensive re-analysis of every problem.

In a recent work [11], the semi-rigid behaviour of connections of planar steel frameworks is implemented in the CEPAO. This paper presents an extension of this general software to the case of space frame for the limit and shakedown analysis problems. 


\section{ASSUMPTIONS AND MODELLING PLASTIC HINGES}

The following assumptions have been made:

- Loading is quasi-static and service load domain is specified by linear constraints;

- The torsional stiffness and the effect of the shear forces are negligible;

- The material behaviour is rigid - perfectly plastic;

- Plastic hinges are located at critical sections.

Modelling plastic hinges

Since the effect of the both shear forces and torsional moments are ignored, the condition of plastic admissibility at the critical sections becomes $\Phi\left(N, M_{y}, M_{z}\right) \leqslant 0$, with $N$ is the normal force and $M_{y}, M_{z}$ are respectively bending moments about to $y$ and $z$ axes. The plastic hinge modelling is described by the choice of net displacement (relative) - force relationship at the critical sections. In present work, the normality rule is adopted:

$$
\left\{\begin{array}{c}
\Delta \\
\theta_{y} \\
\theta_{z}
\end{array}\right\}=\lambda\left\{\begin{array}{l}
\partial \Phi / \partial N \\
\partial \Phi / \partial M_{y} \\
\partial \Phi / \partial M_{z}
\end{array}\right\},
$$

or, symbolically:

$$
\mathbf{e}^{i}=\lambda^{i} \mathbf{N}_{C}^{i},
$$

where $\lambda^{i}$ is the plastic deformation magnitude; $\mathbf{e}^{i}$ is the vector of longitudinal displacement and two rotations of $\mathrm{i}^{\mathrm{th}}$ section; $\mathbf{N}_{C}^{i}$ is a gradient vector of the yield surface $\Phi$.

The application of the LP techniques requires that the nonlinear yield surfaces must be linearized. In civil engineering practices, for bisymmetrical wide-flange shapes, several Standards replace the curvilinear yield surface by a polyhedron sixteen-facet:

$$
\begin{array}{ll}
\alpha_{1} \frac{|N|}{N_{P}}+\alpha_{2} \frac{\left|M_{y}\right|}{M_{P y}}+\alpha_{3} \frac{\left|M_{z}\right|}{M_{P z}}=1 \text { for } & \frac{|N|}{N_{P}} \geqslant \alpha_{0} ; \\
\alpha_{4} \frac{|N|}{N_{P}}+\alpha_{5} \frac{\left|M_{y}\right|}{M_{P y}}+\alpha_{6} \frac{\left|M_{z}\right|}{M_{P z}}=1 \text { for } & \frac{|N|}{N_{P}}<\alpha_{0} ;
\end{array}
$$

where: $M_{P y}, M_{P z}$ are the plastic moment capacity with respect to $y$ and $z$ axis, $N_{P}$ is the squash load, $0 \leqslant \alpha_{0}<1, \alpha_{1}, \ldots, \alpha_{6}$ are the dimensionless coefficients. The Eqs. (2.2a), (2.2b) may also be written:

$$
\begin{array}{lll}
a_{1}|N|+a_{2}\left|M_{y}\right|+a_{3}\left|M_{z}\right|=S_{0} & \text { for } & \frac{|N|}{N_{P}} \geqslant \alpha_{0} ; \\
a_{4}|N|+a_{5}\left|M_{y}\right|+a_{6}\left|M_{z}\right|=S_{0} & \text { for } & \frac{|N|}{N_{P}}<\alpha_{0}
\end{array}
$$

With $S_{0}$ is a referential value, and $a_{1}, \ldots, a_{6}$ are the non-zero coefficients.

At the $i^{\text {th }}$ critical section, the plastic admissibility defined by Eqs. (2.3a), (2.3b) has following form:

$$
\mathbf{Y}^{i} \mathbf{s}^{i} \leqslant \mathbf{s}_{0}^{i}
$$

where matrix $\mathbf{Y}^{i}$ contains the coefficients $a_{1}, \ldots, a_{6} ; \mathbf{s}^{i}$ collects the vector of internal forces; the column matrix $\mathrm{s}_{0}^{i}$ contains the corresponding terms $S_{0}$.

According to the definitions of the matrices $\mathbf{N}_{C}, \mathbf{Y}$, we can see that:

$$
\mathbf{N}_{C}^{i}=\mathbf{Y}^{i T} \text {. }
$$


The detailed form of matrix $\mathbf{N}_{C}$ is below-mentioned by Eq. (3.8).

\section{APPLICATION OF LP}

A systematic treatment of the application of LP in rigid-plastic analysis can be found in [4]. In the present work, we restrict to describe some practical aspects of the CEPAO package applied for the case of 3-D steel frames.

\subsection{General formulation}

In the CEPAO, the canonical formulation of the LP is considered:

$$
\operatorname{Min} \pi=\mathbf{c}^{T} \mathbf{x} \mid \mathbf{W} \mathbf{x}=\mathbf{b}
$$

where $\pi$ is the objective function; $\mathbf{x}, \mathbf{c}, \mathbf{b}$ are respectively the vector of variables, of costs and of second member. $\mathbf{W}$ is called the matrix of constraint. In the sake of simplicity, the objective function has a state variable, and the matrix formulation is arranged such that the basic matrix of the initial solution is appeared clcarly as follows:

$$
\left[\begin{array}{ccc}
-\mathbf{c}_{1}^{T} & 1 & -\mathbf{c}_{2}^{T} \\
\mathbf{W}_{1} & 0 & \mathbf{W}_{2}
\end{array}\right]\left[\begin{array}{l}
\mathbf{x}_{1} \\
\pi \\
\mathbf{x}_{2}
\end{array}\right]=\left[\begin{array}{l}
0 \\
\mathbf{b}
\end{array}\right]
$$

The basic matrix of initial solution is:

$$
\mathbf{X}_{0}=\left[\begin{array}{cc}
1 & -\mathbf{c}_{2}^{T} \\
0 & \mathbf{W}_{2}
\end{array}\right]
$$

Eq. (3.2) can be then written under a general form:

$$
\mathrm{W}^{*} \mathrm{x}^{*}=\mathrm{b}^{*} .
$$

The matrices $\mathbf{W}^{*}, \mathbf{x}^{*}, \mathbf{b}^{*}$ and $\mathbf{X}_{0}$ for both limit and shakedown analysis problems will be accurately calculated in the following sections.

\subsection{Limit analysis by kinematical method}

\section{Kinematical approach}

A kinematically admissible state is defined by a collapse mechanism that satisfies the condition of compatibility. It leads to a positive external power supplied by the reference loading. Based on the upper bound theorem of limit analysis, the kinematical formulation of limit analysis can be stated as a LP problem:

$$
\begin{array}{c|l}
\operatorname{Min} \phi=\mathbf{s}_{0}^{T} \boldsymbol{\lambda} & \begin{array}{l}
\mathbf{N}_{C} \boldsymbol{\lambda}-\mathbf{B d}=\mathbf{0} \\
\mathbf{f}^{T} \mathbf{d}=\xi \\
\lambda \geqslant \mathbf{0}
\end{array}
\end{array}
$$

The safety factor will be obtained by:

$$
\mu_{+}=\phi / \xi
$$

In Eq. (3.4), $\lambda$ is the vector of the plastic deformation magnitude; $\mathrm{B}$ is the kinematic matrix defined in Appendix A; $\mathbf{d}, \mathbf{f}$ are respectively the vector of independent displacements and the vector of external load.

Further reduction of the kinematical approach 
In the kinematical method, the unknowns are the plastic deformation magnitude, lambda, and the independent displacement, $\mathbf{d}$ (negative or positive). In LP procedure we need non-negative variables so that we adopt the change of the variables as in following:

$$
\mathbf{d}^{\prime}=\mathbf{d}+d_{0} \text { so that } \quad \mathbf{d}^{\prime} \geqslant \mathbf{0} .
$$

- The way to fix the value of $d_{0}$, which depends on the real structure, such that $\mathrm{d}^{\prime}$ are always non-negative is explained with details in the reference [12]. Now, problem of Eq. (3.4) becomes:

$$
\begin{array}{c|l}
\operatorname{Min} \phi=\mathbf{s}_{0}^{T} \lambda & \begin{array}{l}
\mathbf{N} \lambda-\mathbf{B d}^{\prime}=-\mathbf{B} d_{0} \\
\mathbf{f}^{T} \mathbf{d}^{\prime}=\xi+\mathbf{f}^{T} d_{0} \\
\lambda, \mathbf{d}^{\prime} \geqslant \mathbf{0}
\end{array} .
\end{array}
$$

Therefore, the vector of variables, matrix of constraint, vector of second member corresponding to the problem of Eq. (3.3) for limit analysis are given below:

$$
\begin{aligned}
& \mathbf{x}^{* T}=\left[\begin{array}{lll}
z & \mathbf{x}^{T} & \eta
\end{array}\right]=\left[\begin{array}{llll}
z & \mathrm{~d}^{\prime T} & \lambda^{T} & \eta
\end{array}\right] \\
& \mathbf{b}^{* T}=\left[\begin{array}{ll}
0 & \mathbf{b}^{T}
\end{array}\right]=\left[\begin{array}{lll}
0 & -\mathbf{B d}_{0} & \xi+\mathbf{f}^{T} d_{0}
\end{array}\right] \\
& \mathbf{W}^{*}=\left[\begin{array}{cccc}
1 & \mathbf{0}^{T} & -\mathbf{s}_{0}^{T} & 0 \\
\mathbf{0} & -\mathbf{B} & \mathbf{N}_{C} & 0 \\
0 & \mathbf{f}^{T} & 0^{T} & 1
\end{array}\right]
\end{aligned}
$$

where $\eta$ is an artificial variable which must be taken out of the basic vector in the simplex process; $\xi$ is a constant chosen in relation with the value of $d_{0}[12]$.

The use of simplex technique we need to find an initial admissible solution such that the initial value of any variable (except the objective function) must be non-negative. To satisfy this requirement, it appears that the following arrangement leads to good behaviours of the automatic calculation:

The linearized condition of plastic admissibility for the $i^{\text {th }}$ section (Eq. (2.4)) may be expanded as follows:
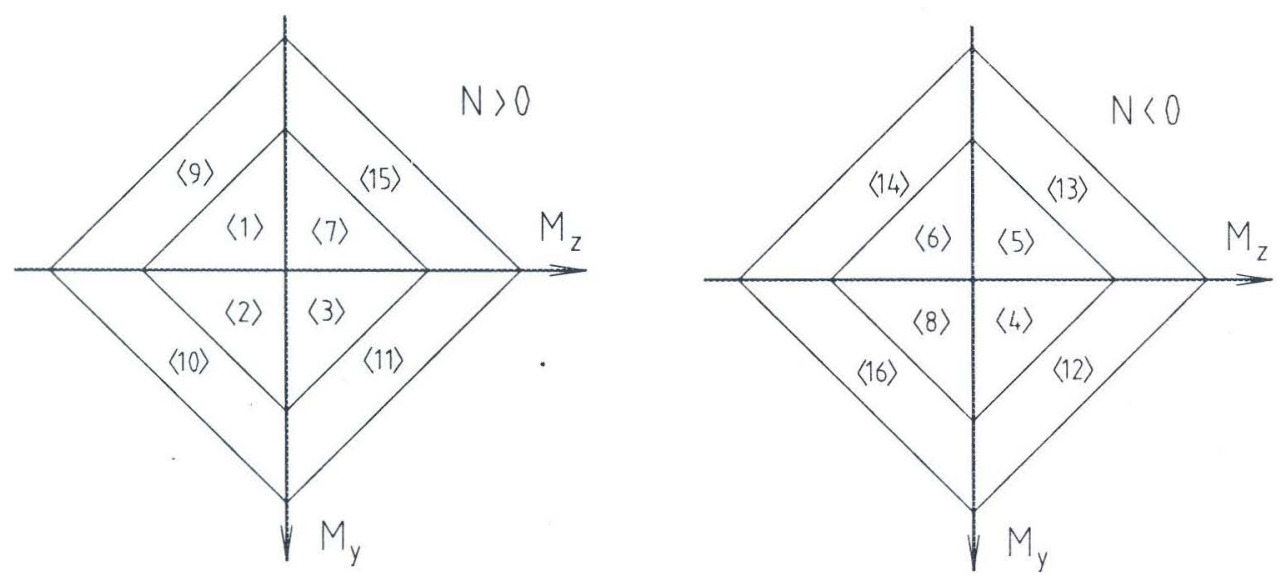

Fig. 1. Projection of the yield surface on the plan $M_{y} O M_{z}$ 


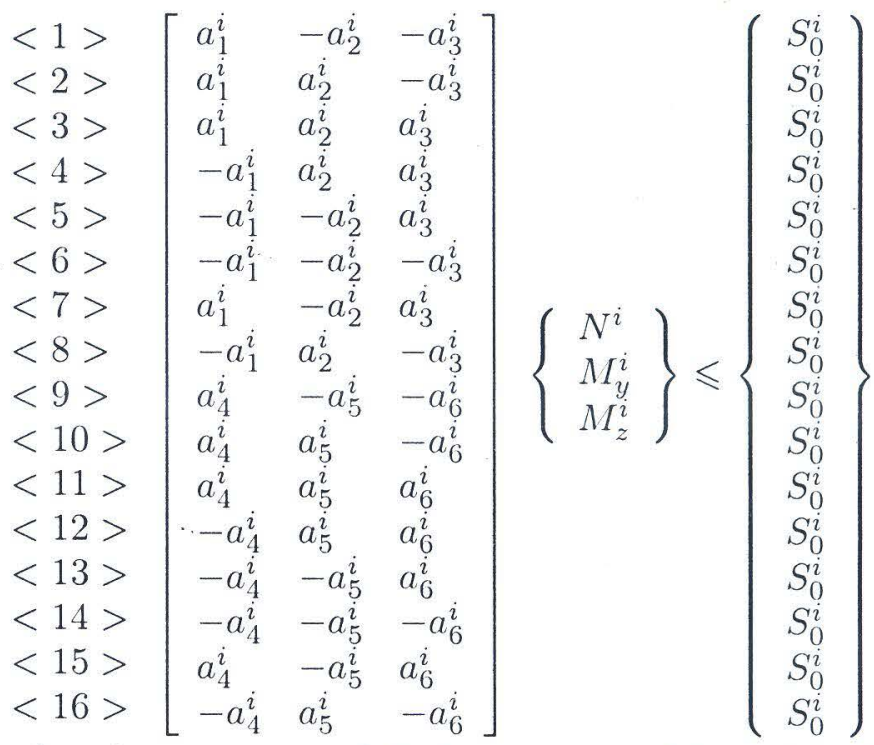

The Fig. 1 describes the projection of 16 planar facets of the polyhedral stress-resultant yield surface corresponding to the 16 inequalities numbered on the Eq. (3.6).

According to Eqs. (2.4), (2.5), we see that Eq. (3.6) can be written under symbolic formulation:

$$
\mathbf{N}_{C}^{i T} \mathbf{s} \leqslant \mathbf{s}_{0}
$$

Put:

$$
\tilde{\mathbf{N}}_{C}^{i}=\left[\begin{array}{lll}
a_{1}^{i} & a_{1}^{i} & a_{1}^{i} \\
-a_{2}^{i} & a_{2}^{i} & a_{2}^{i} \\
-a_{3}^{i} & -a_{3}^{i} & a_{3}^{i}
\end{array}\right]
$$

Let us note that: $\tilde{\mathbf{N}}_{C}^{i}$ is always non-singular because $a_{1}^{i}, a_{2}^{i}, a_{3}^{i}$ are certainly positive.

Then, matrix $\mathbf{N}_{C}^{i}$ in Eq. (3.7) may be decomposed into three sub-matrices:

$$
\mathbf{N}_{C}^{i}=\left[\begin{array}{lll}
\tilde{\mathbf{N}}_{C}^{i} & -\tilde{\mathbf{N}}_{C}^{i} & \overline{\mathbf{N}}_{C}^{i}
\end{array}\right]
$$

with $\overline{\mathbf{N}}_{C}^{i}$ is the rest of $\mathbf{N}_{C}^{i}$ after deducting $\tilde{\mathbf{N}}_{C}^{i}$ and $-\tilde{\mathbf{N}}_{C}^{i}$.

The decomposition of matrix $\mathbf{N}_{C}^{i}$ leads then to the following form:

$$
\begin{aligned}
\mathbf{s}_{0}^{i T} & =\left[\begin{array}{lll}
\tilde{\mathbf{s}}_{0}^{i T} & \tilde{\mathbf{s}}_{0}^{i T} & \overline{\mathbf{s}}_{0}^{i T}
\end{array}\right]=\left[\begin{array}{lll}
S_{0}^{i} & \cdots & S_{0}^{i}
\end{array}\right] ; \\
\lambda^{i T} & =\left[\begin{array}{lll}
\tilde{\lambda}^{i T} & \tilde{\lambda}_{+3}^{i T} & \bar{\lambda}^{i T}
\end{array}\right],
\end{aligned}
$$

where:

$$
\begin{aligned}
\tilde{\lambda}^{i T} & =\left[\begin{array}{lll}
\lambda_{1}^{i} & \lambda_{2}^{i} & \lambda_{3}^{i}
\end{array}\right] ; \\
\tilde{\lambda}_{+3}^{i T} & =\left[\begin{array}{lll}
\lambda_{4}^{i} & \lambda_{5}^{i} & \lambda_{6}^{i}
\end{array}\right] ; \\
\bar{\lambda}^{i} & =\left[\begin{array}{lll}
\lambda_{7}^{i} & \ldots & \lambda_{16}^{i}
\end{array}\right] .
\end{aligned}
$$

Let now $\mathbf{S}^{i}$ be a diagonal matrix, such that:

$$
\mathbf{S}^{i}=\operatorname{diag}\left[1 \times \operatorname{sign} \text { of }\left(\left(\tilde{\mathbf{N}}_{C}^{i}\right)^{-1} \mathbf{b}^{i}\right)\right],
$$


with:

$$
\mathbf{b}^{i T}=\left[\begin{array}{lll}
\mathrm{b}_{3(i-1)+1} & \mathrm{~b}_{3(i-1)+2} & \mathrm{~b}_{3(i-1)+3}
\end{array}\right]
$$

Let $\mathbf{E}$ be a unity matrix of dimension $3 \times 3$.

And consider now the new plastic deformation magnitude distribution:

$$
\lambda^{\mathrm{i} T \mathrm{~T}}=\left[\begin{array}{lll}
\tilde{\lambda}^{\mathrm{i}^{\prime} \mathrm{T}} & \tilde{\lambda}_{+3}^{\mathrm{i} T} & \bar{\lambda}^{\mathrm{iT}}
\end{array}\right]
$$

in which:

$$
\begin{gathered}
\tilde{\lambda}^{\mathrm{i}^{\prime}}=0.5\left(\mathbf{E}+\mathbf{S}^{i}\right) \tilde{\lambda}^{i}+0.5\left(\mathbf{E}-\mathbf{S}^{i}\right) \tilde{\lambda}_{+3}^{i} \\
\tilde{\lambda}_{+3}{ }^{\prime}=0.5\left(\mathbf{E}-\mathbf{S}^{i}\right) \tilde{\lambda}^{i}+0.5\left(\mathbf{E}+\mathbf{S}^{i}\right) \tilde{\lambda}_{+3}^{i} .
\end{gathered}
$$

With mentioned arrangement, and if the case of initial basis of variables is

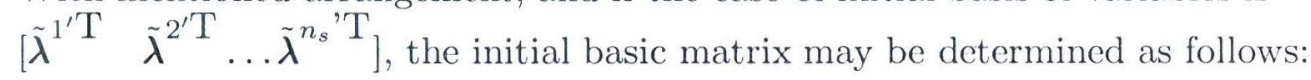

in which, $n_{s}$ is the number of critical sections.

$$
\mathbf{X}_{0}=\left[\begin{array}{llllll}
1 & -\tilde{\mathbf{s}}_{0}^{1 T} & -\tilde{\mathbf{s}}_{0}^{2 \mathrm{~T}} & \ldots & -\tilde{\mathbf{s}}_{0}^{\mathrm{n}_{s} \mathrm{~T}} & 0 \\
0 & \tilde{\mathbf{N}}_{C}^{1} \mathbf{S}^{1} & 0 & \ldots & 0 & 0 \\
0 & 0 & \tilde{\mathbf{N}}_{C}^{2} \mathbf{S}^{2} & \ldots & 0 & 0 \\
\vdots & \vdots & \vdots & \ldots & \vdots & \vdots \\
0 & 0 & 0 & \ldots & \tilde{\mathbf{N}}_{C}^{n_{s}} \mathbf{S}^{n_{s}} & 0 \\
0 & 0^{T} & 0^{T} & \ldots & 0^{T} & 1
\end{array}\right]
$$

Easily, we may demonstrate that the initial solution:

is certainly non-negative.

$$
\mathbf{x}_{0}=\mathbf{X}_{0}^{-1} \mathbf{b}
$$

Direct calculation of the internal force distribution

The strain rate at critical sections is chosen as variables in kinematical approach. The collapse factor and mechanism are given as output. To obtain the internal force distribution while avoiding the static approach, the dual properties of LP are used. The physical significance of the dual variables may be established as follows:

The canonical dual from of the LP problem of equation (3.1) is:

$$
\operatorname{Max}\left(\mathbf{b}^{T} \mathbf{y}+\mathbf{0}^{T} \mathbf{h}\right) \mid \begin{aligned}
& \mathbf{W}^{T} \mathbf{y}+\mathbf{h}=\mathbf{c} \\
& \mathbf{h} \geqslant \mathbf{0}
\end{aligned},
$$

in Eq. (3.9), $\mathbf{y}^{T}=\left[\begin{array}{ll}\mathbf{s}^{T} & \mu_{-}\end{array}\right]$,

and $\mathbf{h}$ are the non-negative slack variables:

$$
\begin{aligned}
\mathbf{h}^{T} & =\left[\begin{array}{lllll}
\mathbf{0}^{T} & \mathbf{h}^{1 T} & \mathbf{h}^{2 \mathrm{~T}} & \ldots & \mathbf{h}^{n_{s} \mathrm{~T}}
\end{array}\right], \text { with : } \\
\mathbf{h}^{\mathrm{iT}} & =\left[\begin{array}{llll}
\tilde{\mathbf{h}}^{\mathrm{iT}} & \tilde{\mathbf{h}}_{+3}^{\mathrm{iT}} & \overline{\mathbf{h}}^{i}
\end{array}\right] .
\end{aligned}
$$

It may be seen from the equality (3.9) that the internal forces are related to the slack variables $\mathbf{h}$ :

$$
\mathbf{s}^{i}=\left(\tilde{\mathbf{N}}_{C}^{\mathrm{iT}}\right)^{-1}\left(\tilde{\mathbf{s}}_{0}^{i}-\tilde{\mathbf{h}}^{i}\right)
$$


It can be shown that the slack variables $\mathbf{h}$ are identified exactly as the reduced costs $\bar{c}$ of the primal problem (3.3):

$$
\mathbf{h}=\overline{\mathbf{c}}=\left(\mathbf{X}_{\mathrm{op}}^{-1}(1,:)\right) \mathbf{W}^{*}
$$

where $\mathbf{X}_{\mathrm{Op}}^{-1}(1,:)$ is the first row of the inverses basic matrix at optimal solution.

The reduced costs $\overline{\mathbf{c}}$ necessary for the convergence test of the simplex algorithm are variable in the output of the primal calculation. The automatic computation by (3.10) of the internal forces distribution is independent of the type of collapse: partial, complete or over-complete.

\subsection{Shakedown analysis by kinematical method}

\section{Reduced kinematic approach}

Based on the upper bound theorem of shakedown analysis, the safely factor can be determined by minimizing the kinematically admissible multiplier. Since the service load domain is specified by linear constraints, the kinematic approach leads to a LP problem:

$$
\begin{array}{c|l}
\text { Min } \phi=\mathbf{s}_{0}^{T} \lambda & \begin{array}{l}
\mathbf{N} \lambda-\mathbf{B d}=0 \\
\mathbf{s}_{E}^{T} \mathbf{N}_{C} \lambda=\xi \\
\lambda \geqslant 0
\end{array}
\end{array}
$$

where $\mathbf{s}_{E}$ is the envelope of the elastic responses of the considered loading domain.

The safety factor will be obtained by:

$$
\mu_{s+}=\phi / \xi
$$

As in the limit analysis, by an appropriate choice of $d_{0}$ such that:

$$
\mathrm{d}^{\prime}=\mathbf{d}+\mathrm{d}_{0} \geqslant 0,
$$

and by using the new plastic deformation magnitude distribution, the vector of variables, matrix of constraints and vector of second member corresponding to the problem (3.3) for shakedown analysis have the following form:

$$
\begin{gathered}
\mathbf{x}^{* T}=\left[\begin{array}{llll}
z & \mathbf{d}^{\prime} & \lambda & \eta
\end{array}\right] ; \\
\mathbf{b}^{* \mathrm{~T}}=\left[\begin{array}{llll}
0 & -\mathrm{Bd}_{0} & \xi
\end{array}\right] ; \\
\mathbf{W}^{*}=\left[\begin{array}{lllll}
1 & 0^{T} & -\mathbf{s}_{0}^{T} & 0 \\
0 & -\mathbf{B} & \mathbf{N}_{C} & 0 \\
0 & 0^{T} & \mathbf{s}_{E}^{T} \mathbf{N}_{C} & 1
\end{array}\right]
\end{gathered}
$$


With initial basic matrix:

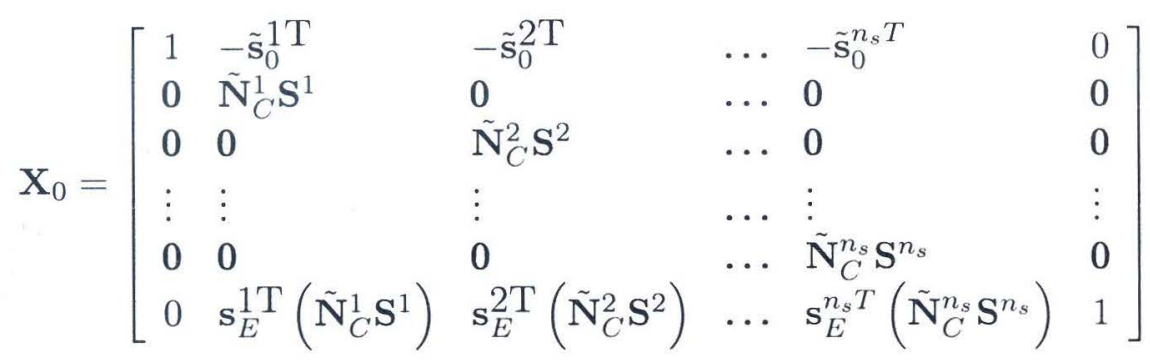

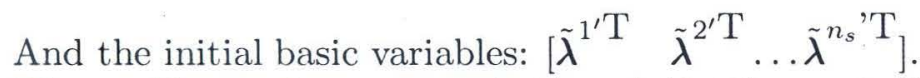

The problems of equations (3.5) and (3.11) are similar except for the choice of the initial admissible point in the permissible domain and the shakedown analysis requires preliminary calculation of elastic responses.

Direct calculation of the residual internal force distribution

Again the dual form of equation (3.11) is written now similarly to equation (3.9) with:

$$
\mathbf{y}^{T}=\left[\begin{array}{ll}
\boldsymbol{\rho}^{T} & \mu_{s-}
\end{array}\right] ; \quad \mathbf{h}^{T}=\left[\begin{array}{llll}
\mathbf{0}^{T} & \mathbf{h}^{1 \mathrm{~T}} & \mathbf{h}^{2 \mathrm{~T}} & \ldots \mathbf{h}^{n_{s} \mathrm{~T}}
\end{array}\right]
$$

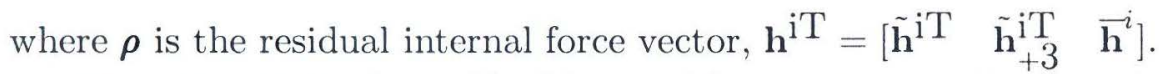

From Eq. (3.9), the residual internal forces are related to the slack variables $\mathbf{h}$ as the following relation:

$$
\rho^{i}=\left(\tilde{\mathbf{N}}_{C}^{\mathrm{iT}}\right)^{-1}\left(\tilde{\mathbf{s}}_{0}^{i}-\mu_{s} \tilde{\mathbf{N}}_{C}^{i} \mathbf{s}_{E}-\tilde{\mathbf{h}}^{i}\right)
$$

As $\mathbf{h}$ is identified to be the reduced costs of the primal problem (3.11), the distribution of residual internal force is directly obtained without performing a second static approach.

\section{NUMERICAL EXAMPLES AND DISCUSSIONS}

The present of two following examples aim at the both of the comparison the CEPAO' results with those of some other authors, and the comparison the results analysed by different models in CEPAO. Therefore, we present not only the results given by limit and shakedown analysis but also those calculated by step-by-step method (the content not present in this paper).

In those examples, with the elastic-plastic analysis by hinge-by-hinge method, the plastic interaction function proposed by Orbison [13] for compact wide-flange sections is introduced in the CEPAO:

$$
\Phi=1.15 n^{2}+m_{z}^{2}+m_{y}^{4}+3.67 p^{2} m_{z}^{2}+3 p^{6} m_{y}^{2}+4.65 m_{y}^{2} m_{z}^{2}-1=0,
$$

in which $n=N / N_{p}$ is ratio of the axial force to the squash load, $m_{y}=M_{y} / M_{p y}$ and $m_{z}=$ $M_{z} / M_{p z}$ are the ratios of the minor-axis and major-axis moments to the corresponding plastic moments, respectively. This yield surface is already used in several references [14-16] that we consult to compare with our results.

In the direct analysis by LP, the plastic strength of cross sections using in the AISC [17] is installed in the CEPAO, with the value of $a_{1}, \ldots, a_{6}$ and $\alpha$ in the Eqs. (2.3a), (2.3b) are: $a_{1}=S_{0} / N_{p} ; a_{2}=8 S_{0} / 9 M_{y p}, a_{3}=8 S_{0} / 9 M_{z p}, a_{4}=S_{0} / 2 N_{p}, a_{5}=S_{0} / M_{y p}$, $a_{6}=S_{0} / M_{z p}, \alpha=0.2$. 
Example a -Six story space frame: Fig. 2 shown Orbinson's six-story space frame. The yield strength of all members is $250 \mathrm{MPa}$ and Young'modulus is 206.850 MPa. Uniform floor pressure of $4.8 \beta_{1} \mathrm{kN} / \mathrm{m}^{2}$; win loads are simulated by point loads of $26.7 \beta_{2} \mathrm{kN}$ in the $Y$-direction at every beam-column joint.
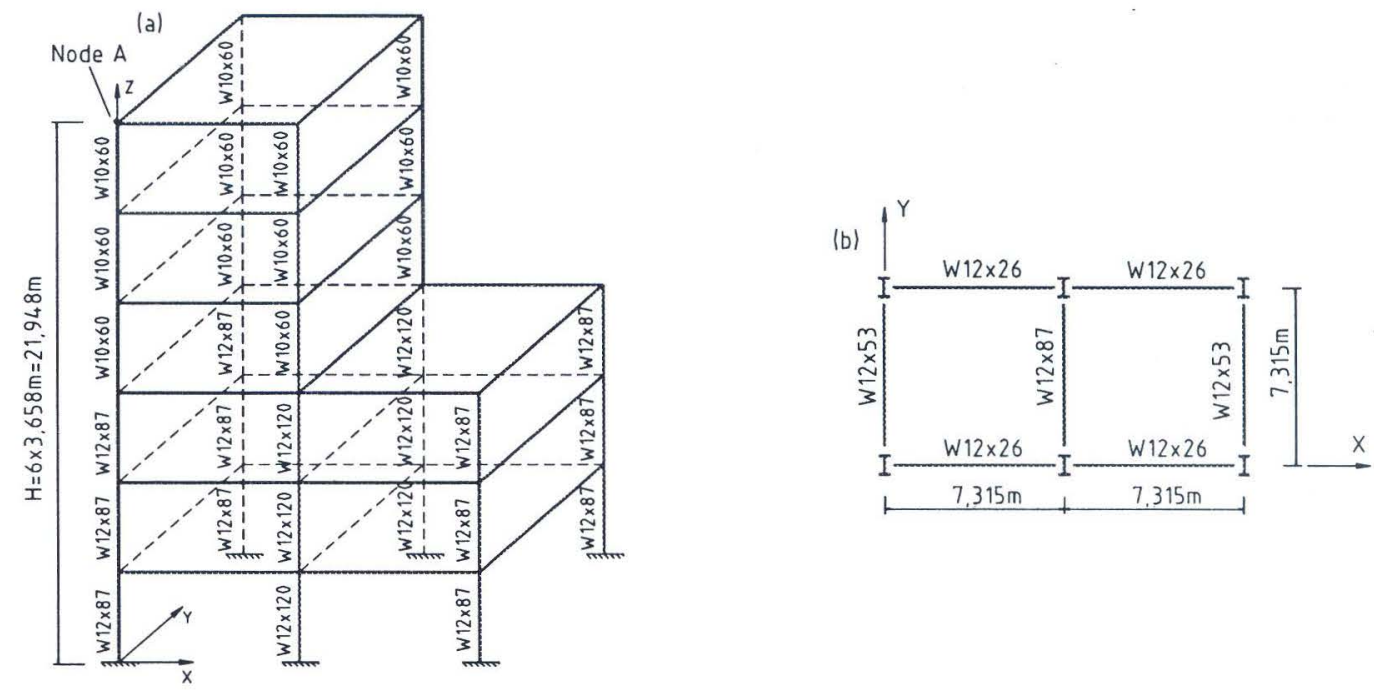

Fig. 2. Example a-Six story space frame (a-perspective view, b-plan view)

Example $b$-Twenty story space frame: Twenty-story space frame with dimensions and properties shown in Fig. 3. The yield strength of all members is $344.8 \mathrm{MPa}$ and Young'modulus is $200 \mathrm{MPa}$. Uniform floor pressure of $4.8 \beta_{1} \mathrm{kN} / \mathrm{m}^{2}$; win loads $=0.96 \beta_{2} \mathrm{kN} / \mathrm{m}^{2}$, acting in the $Y$ direction.

Concerning the loading domain (for two examples), two cases are considered for shakedown analysis: a) $0 \leqslant \beta_{1} \leqslant 1,0 \leqslant \beta_{2} \leqslant 1$ and b) $0 \leqslant \beta_{1} \leqslant 1,-1 \leqslant \beta_{2} \leqslant 1$. For fixed or proportional loading, we obviously must have: $\beta_{1}=\beta_{2}=1$. The uniformly distributed loads are lumped at the joints of frames.

The load ratios corresponding to the elastic-plastic second order given by CEPAO compare well with those of some authors (Table 1). The results analysed by CEPAO with different methods shown on the table 2, Fig. 4, and Fig. 5 point out:

- An expectable coincidence of results calculated by limit analysis and elastic-plastic analysis first order, it allow to deduce: the good convergence between the dual methods in the CEPAO (kinematic and static method); and the good correlation between the Orbison'yeild surface and this in AISC-LRFD.

- In the case of symmetric horizontal loading (seismic load or win load), the load multipliers determined by shakedown analysis are the smallest (alternating plastic occurs).

\section{CONCLUSIONS}

Though the performed work, we can withdraw the following conclusions: 

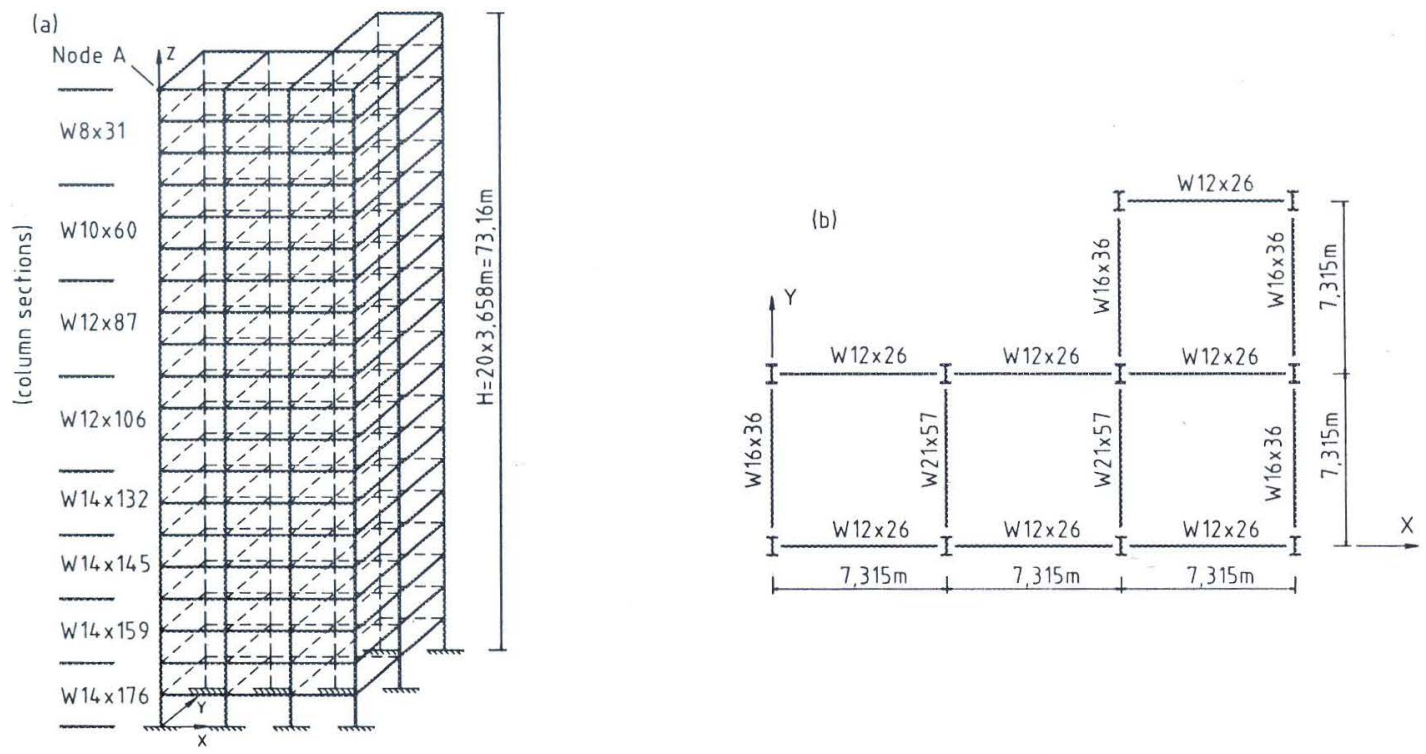

Fig. 3. Example b- Twenty story space frame (a- perspective view; b- plan view)

Table 1. Comparison of results (elastic-plastic 2nd order)

\begin{tabular}{|l|l|l|l|}
\hline \multirow{2}{*}{ Author } & \multirow{2}{*}{ Model } & Load multiplier & \\
\cline { 3 - 4 } & & Example a & Example b \\
\hline J. Y. R. Liew - 2000[14] & Plastic hinge & 2.010 & - \\
\hline S. E. Kim -2001[15] & Plastic hinge & 2.066 & - \\
\hline C. G. Chiorean - 2005[16] & $\begin{array}{l}\text { Distributed plas- } \\
\text { ticity }\end{array}$ & $2.124(\mathrm{n}=30)$ & $1.062(\mathrm{n}=30)$ \\
\hline C. G. Chiorean -2005[16] & $\begin{array}{l}\text { Distributed plas- } \\
\text { ticity }\end{array}$ & $1.998(\mathrm{n}=300)$ & $1.005(\mathrm{n}=300)$ \\
\hline Cuong Ngo-Huu - 2006[18] & Fiber plastic hinge & 2.040 & 1.003 \\
\hline J. Y. R. Liew - 2001[19] & Plastic hinge & - & 1.031 \\
\hline X. M. Jiang - 2002[20] & Fiber element & - & 1.000 \\
\hline CEPAO - 2007 & Plastic hinge & 2.033 & 1.024 \\
\hline
\end{tabular}

- It appears in this paper that the simplex technique constitutes an efficient tool in the automatic rigid-plastic analysis of 3D steel frameworks.

- Without difficulty other alternative yield surfaces may be introduced in the CEPAO as proposed in different current Standards (American Standard, European Standard, ....).

- The present version of 3D-CEPAO is still an auto-controlled algorithm. Indeed, we can verify easily the results by using resident equivalent procedure. For example, limit analysis and analysis hinge -by-hinge method must lead to the same load factor, while they are based on tow dual methods (kinematic method and static method).

- The present extensions suggest that with its automatic aspects, CEPAO may constitute a source for future implementation and researches in civil engineering practices today. 
Table 2. Results given by CEPAO with different analysis

\begin{tabular}{|l|l|l|l|}
\hline \multirow{2}{*}{ Method } & Load multiplier & & Limit state \\
\cline { 2 - 4 } & Example a & Example b & $\begin{array}{l}\text { Formation of a } \\
\text { mechanism }\end{array}$ \\
\hline Hinge-by-hinge, second order & 2.489 & 1.689 & Unstableness \\
\hline Limit analysis & 2.412 & 1.033 & $\begin{array}{l}\text { Formation of a } \\
\text { mechanism }\end{array}$ \\
\hline $\begin{array}{l}\text { Shakedown analysis, domain } \\
\text { load a }\end{array}$ & 2.311 & 1.614 & $\begin{array}{l}\text { Incremental } \\
\text { plasticity }\end{array}$ \\
\hline $\begin{array}{l}\text { Shakedown analysis, domain } \\
\text { load b }\end{array}$ & 1.670 & 0.987 & $\begin{array}{l}\text { Alternating } \\
\text { plasticity }\end{array}$ \\
\hline
\end{tabular}

In the near future, we hope to present the rigid-plastic design problems of 3-D steel frames in the CEPAO.

\section{Appendix A: Compatibility relation}

Let $\mathbf{e}_{k}^{T}=\left[\begin{array}{llllll}\Delta_{A} & \theta_{y A} & \theta_{z A} & \Delta_{B} & \theta_{y B} & \theta_{z B}\end{array}\right]$ be the vector of the axial displacement and the net rotation of the member ends (Fig. A1a). Assemble for the frameworks (system of the elements) we have the vector $\mathbf{e}$.

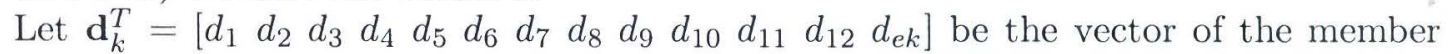
independent displacements in the global coordinate system $O X Y Z$, like shown in Fig. A1b. Assemble for the frameworks we obtain the vector $\mathbf{d}$.

In the sense of limit analysis, we may think that: $d_{1}, d_{2}, d_{3}, d_{7}, d_{8}, d_{9}$ are the displacements corresponding to the deflection mechanisms (beam and sideways mechanisms); $d_{4}$, $d_{5}, d_{6}, d_{10}, d_{11}, d_{12}$ are the displacements showing the joints mechanisms; $d_{e k}$ displacement in the longitudinal direction of the element, describes the bar mechanisms (the bar translates along this axis). Since the torsional stiffness of the elements is negligible, we must eliminate the degree of freedom that only provokes pure torsion in the bars.

The compatibility relation is defined as:

$$
\mathbf{e}=\mathbf{B d}
$$

where $\mathbf{B}$ namely the kinematic matrix that is determined by:

$$
\mathbf{B}=\sum_{k} \mathbf{A}_{k} \mathbf{T}_{k} \mathbf{L}_{k}
$$

In Eq. (A1), $\mathbf{L}_{k}$ is a localization Boolean matrix of member $k$; and 

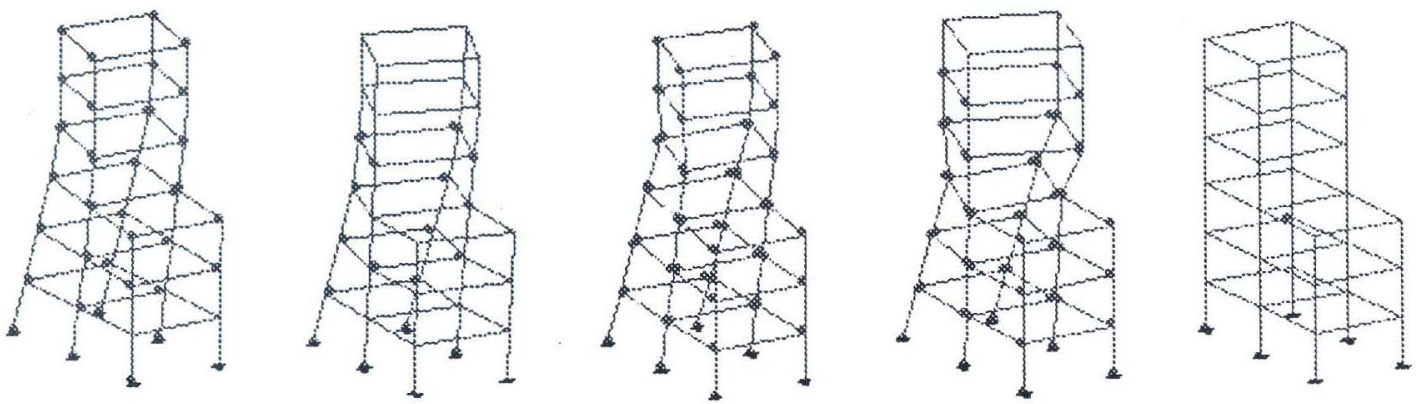

(a) - Example a
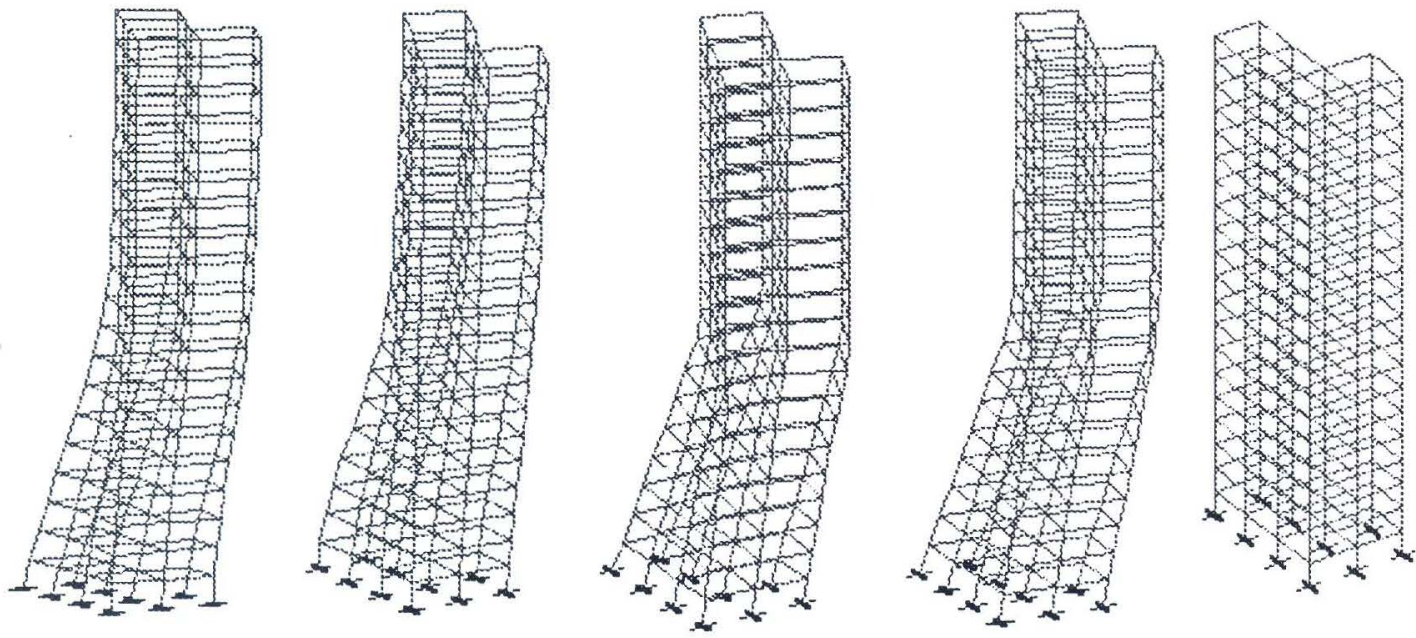

\section{(b) - Example b}

(From the left to the right: Elastic-plastic first order; Elastic-plastic second order; Limit analysis; Shakedown analysis, load domain a; Shakedown analysis, load domain b. The points on the Fig. (a) are the plastic hinges)

Fig. 4. Deformation at limit state given by CEPAO

$$
\mathbf{A}_{k}=\left[\begin{array}{cccccccccccc}
1 & 0 & 0 & 0 & 0 & 0 & 0 & 0 & 0 & 0 & -1 \\
0 & 0 & - & \frac{1}{l_{k}} & 1 & 0 & 0 & 0 & \frac{1}{l_{k}} & 0 & 0 & 0 \\
0 & -\frac{1}{l_{k}} & 0 & 0 & -1 & 0 & \frac{1}{l_{k}} & 0 & 0 & 0 & 0 \\
0 & 0 & 0 & 0 & 0 & 1 & 0 & 0 & 0 & 0 & -1 \\
0 & 0 & \frac{1}{l_{k}} & 0 & 0 & 0 & 0 & -\frac{1}{l_{k}} & -1 & 0 & 0 \\
0 & \frac{1}{l_{k}} & 0 & 0 & 0 & 0 & -\frac{1}{l_{k}} & 0 & 0 & 1 & 0
\end{array}\right],
$$




- Hinge-by-hinge first order
- Limit analysis
- - Shakedown analysis, load domain b
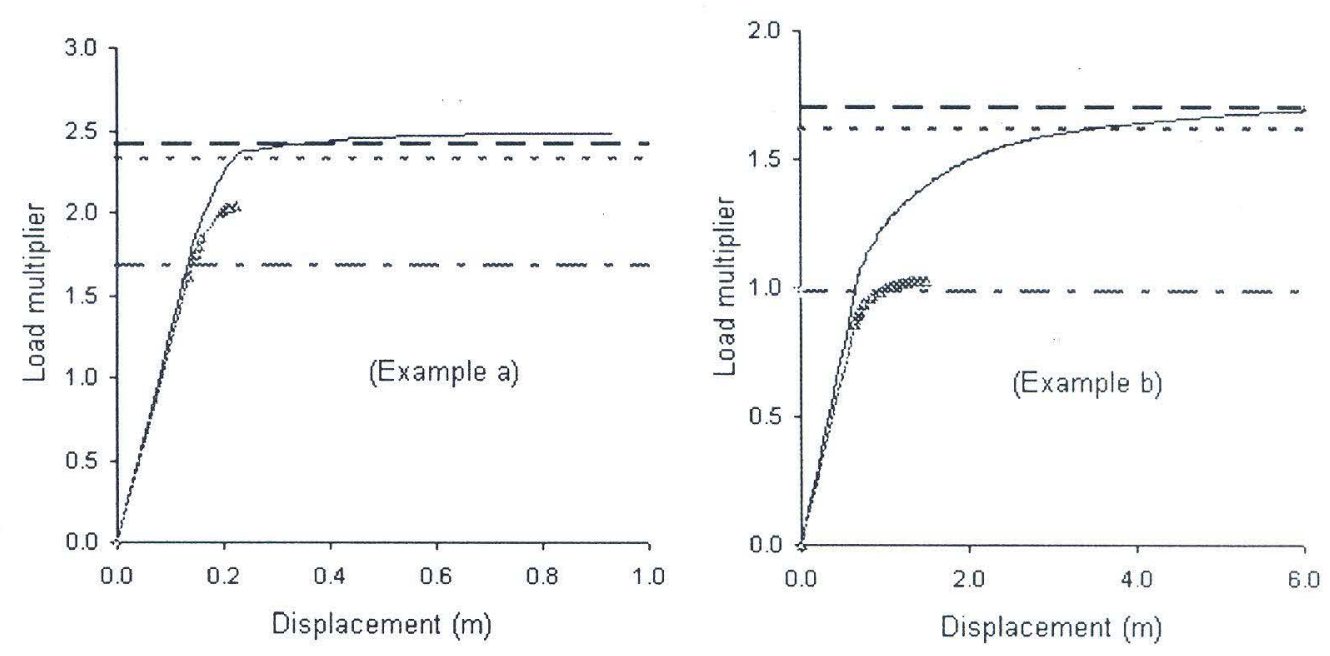

Fig. 5. Load-deflection results at point A (Fig.2, Fig.3) given by CEPAO
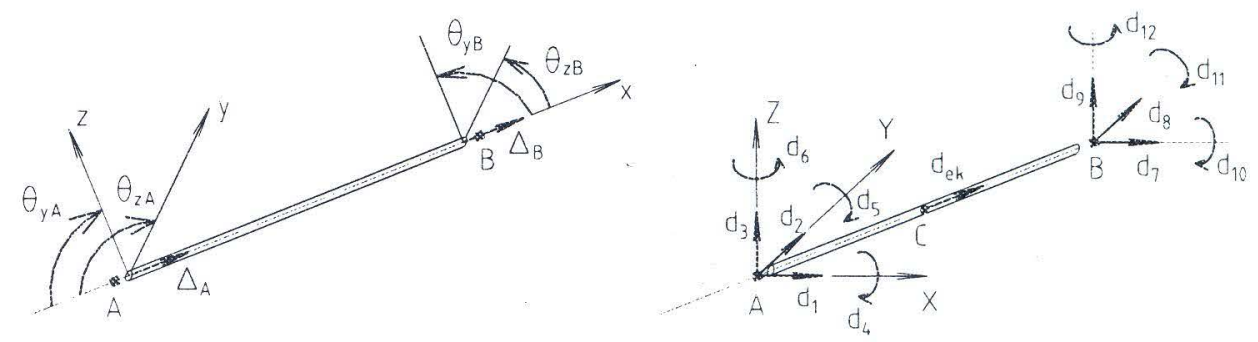
a - Relative displacements
b - Member'independent
at critical sections
displacements $\{$ global axis\}

Fig. 6. Member $\mathrm{k}$

$$
\mathbf{T}_{k}=\left[\begin{array}{ccccc}
\mathbf{C}_{k} & & & & \\
& \mathbf{C}_{k}^{\prime} & & & \\
& & \mathbf{C}_{k} & & \\
& & & \mathbf{C}_{k}^{\prime} & \\
& & & & 1
\end{array}\right]
$$

with: 


$$
\begin{aligned}
\mathbf{C}_{k} & =\left[\begin{array}{lll}
c_{11} & c_{12} & c_{13} \\
c_{21} & c_{22} & c_{23} \\
c_{31} & c_{32} & c_{33}
\end{array}\right] \text { is the matrix of direction cosines of element } k \\
\mathbf{C}_{k}^{\prime} & =\left[\begin{array}{lll}
c_{21} & c_{22} & c_{23} \\
c_{31} & c_{32} & c_{33}
\end{array}\right] .
\end{aligned}
$$

\section{REFERENCES}

1. P. G. Hodge, Plastic analysis of structures. McGraw Hill, New York, 1959.

2. B. G. Neal, The plastic method of structural analysis, Chapman \& Hall, London, 1970.

3. Ch. Massonnet, M. Save, Lastique des constructions Volume 1, Nelissen, Belgique, 1976.

4. M. Z. Cohn, G. Maier, Engineering Plasticity by Mathematical Programming, University of Waterloo, Canada, 1979.

5. Milan Jir sek, Zdenek P. Bažant, Inelastic Analysis of Structure, John Wiley \& Sons, LTD, 2001.

6. Nguyen Dang Hung, CEPAO-an automatic program for rigid-plastic and elastic-plastic, analysis and optimization of frame structure, Engineering Structures 6 (1984) 33-50.

7. Nguyen Dang Hung, Géry de Saxcé, Analyse et dimensionnement plastique des structures à barres dans les conditions de stabilité, Construction métallique (3) 1981.

8. Nguyen Dang Hung, Sur la plasticité et le calcul des états limites par éléments finis, Thèse de doctorat spécial, l'Université de Liège, 1984.

9. Nguyen-Dang Hung, Sur l'utilisation du simplexe dans le CEPAO 82, Rapport interne $n^{\circ} 133$ du Laboratoire de Mécanique des Matériaux et de Stabilité des Constructions, l'Université de Liège, Belgique, 1983.

10. Géry de Saxcé, L. M. Ayina ohandja, Une méthode automatique de calcul de l'effet P - Delta pour l'analyse pas - à - pas des ossatures planes, Construction métallique (3) 1985.

11. Nguyen Dang Hung, Hoang Van Long, A United Algorithm for Limit State Determination of Frames with Semi-Rigid Connections, Collection of papers from Prof. Nguyen Dang Hung's former students, Vietnam National University Ho Chi Minh City Publishing House 2006: 228 - 248.

12. Nguyen-Dang Hung, Hoang-Van Long, On the change of variables in the calculation plastic of structures by LP in the CEPAO program, Internal Report of Division LTAS-Fracture Mechanics, University of Liège, 2006.

13. James G. Orbison, William McGUIRE, John F. ABEL, Yield surface applications in nonlinear steel frame analysis, Computer Method in Applied Mechanics and Engineering $331982557-573$.

14. J. Y. Richard Liew, H. Chen, N. E. Shanmugam, W. F. Chen. Improved nonlinear plastic hinge analysis of space frame structures, Engineering Structures 22 (2000) 1324-1338.

15. Seung - Eock Kim, Moon - Ho Park, Se - Huy Choi. Direct design of three-dimensional frames using advanced analysis, Engineering Structures 23 (2001) 1491-1502.

16. C. G. Chiorean, G. M. Barsan. Large deflection distributed plasticity analysis of 3D steel frameworks, Computers \& Structures 83 (2005) 1555-1571.

17. AISC, Load and Resistance Factor Design Specification for Steel Buildings, American Institute of Steel Construction, Chicago, 1993.

18. Cuong Ngo-Huu, Seung-Eclok Kim, Jung-Ryul Oh, Nonlinear analysis of space frames using fiber plastic hinge concept, Engineering Structures 29 (2006) 649-657.

19. J. Y. Richard Liew, Hong Chen, N. E. Shanmugam, Inelastic analysis of steel frames with composite beams, ASCE Journal Engineering Structures 127 (2) (2001) 194-202.

20. Xiao-Mo Jiang, Heng Chen, J. Y. Richard Liew, Spread-of-plasticity analysis of three-dimensional steel frames, J. Constructional Steel Research 58 (2002) 193-212. 


\section{PHÂN TÍCH THÍCH NGHI VÀ GIỚI HẠN TỰ DộNG CỦA GIÀN THÉP 3-D}

Bài báo này trình bầy một thuật toán hiệu quả cho cả phân tích thích nghi và giới hạn của giàn thép 3-D bởi phương pháp động học dùng kỹ thuật quy hoạch tuyến tính. Nhiều tính chất trong ứng dụng của quy hoạch tuyến tính đối với phân tích rắn-dèo của giàn thép 3 chiều được thảo luận, như: sự đổi biến, chọn tự động ma trận cơ sở ban đầu đối với thuật toán đơn hình, tính toán trực tiếp của các biến đối ngẫu bằng phương pháp đối ngẫu cơ bản. Một số ví dụ bằng số được trình bầy để minh họa tính tổng quát và hiệu quả của phương pháp đã đề nghị và chương trình tính. 